\title{
BMJ Open Regular running in an air-polluted environment: physiological and anthropometric protocol for a prospective cohort study (Healthy Aging in Industrial Environment Study - Program 4)
}

\author{
Lukas Cipryan (1) , ${ }^{1}$ Petr Kutac, ${ }^{1}$ Tomas Dostal, ${ }^{1}$ Matthew Zimmermann, ${ }^{1}$ \\ Miroslav Krajcigr, ${ }^{1}$ Vera Jandackova, ${ }^{1,2}$ Radim Sram, ${ }^{3,4}$ Daniel Jandacka, ${ }^{1}$ \\ Peter Hofmann ${ }^{5}$
}

To cite: Cipryan L, Kutac P, Dostal T, et al. Regular running in an air-polluted environment: physiological and anthropometric protocol for a prospective cohort study (Healthy Aging in Industrial Environment Study - Program 4). BMJ Open 2020;10:e040529. doi:10.1136/ bmjopen-2020-040529

- Prepublication history for this paper is available online. To view these files, please visit the journal online (http://dx.doi. org/10.1136/bmjopen-2020040529).

Received 19 May 2020 Revised 27 October 2020 Accepted 18 November 2020

Check for updates

(C) Author(s) (or their employer(s)) 2020. Re-use permitted under CC BY-NC. No commercial re-use. See rights and permissions. Published by BMJ.

For numbered affiliations see end of article.

Correspondence to Assoc. Prof. Lukas Cipryan; lukas.cipryan@osu.cz

\section{ABSTRACT}

Introduction Ambient air pollution is a global environmental problem, which causes adverse health effects and premature deaths worldwide. Although regular exercise and physical activity have evident health benefits, the influence of long-term air pollution exposure during regular outdoor running has not been definitively clarified. Methods and analysis This study protocol describes the physiological and anthropometric perspectives of the 'Healthy Aging in Industrial Environment' Study Programme 4 (4HAIE). The $4 \mathrm{HAIE}$ research project is intended to be a single-centre, prospective, longitudinal and multidisciplinary cohort study. The presented study protocol describes the cross-sectional measurements and analyses. Overall, 1500 adult participants (age 18-65 years), runners and inactive individuals, living in a high or low air-polluted area of the Czech Republic will be recruited. We will measure and analyse biomarkers of oxidative stress and inflammation in the blood, exercise capacity (graded exercise test and spiroergometry), blood pressure, lung function (spirometry), cardiac autonomic regulation and anthropometry (body composition).

Ethics and dissemination The 4HAIE study protocol has already been approved by the Ethics Committee of the University of Ostrava (3/2018). A detailed participant information sheet will be provided to each individual prior to obtaining their written informed consent. The study poses little to no risk to participants. The findings of this study will be disseminated at regional and international conferences, in peer-reviewed journals and via social and broadcast media.

\section{INTRODUCTION}

It has been demonstrated that 9 out of 10 people breathe air containing high levels of pollutants. Air pollution (AP) contributes to the premature mortality of an estimated 7 million people worldwide annually (WHO, 2019). ${ }^{1}$ For example, fine particulate matter
Strengths and limitations of this study

- The presented study is part of the multidisciplinary research project with extensive cohorts of runners and inactive individuals ( $\mathrm{N}=1500$ in total).

- Participant recruitment into the study cohort is conducted by a professional marketing and social research agency using stratified quota sampling to ensure representation by age, sex and physical activity status, which enables to generalise the study results.

- The first wave of this observational study will provide cross-sectional laboratory data; however, the Healthy Aging in Industrial Environment Study Program 4 study is intended to become longitudinal and future laboratory follow-up data collection is planned.

- The study focuses on the long-term effect of living and running in a high or low air-polluted region. The acute effects of air pollution are not considered.

$<2.5 \mu \mathrm{m} \quad\left(\mathrm{PM}_{2.5}\right)$ is considered a leading cause of global morbidity and mortality as it promotes the development of chronic cardiometabolic conditions including atherosclerosis, hypertension and diabetes mellitus. ${ }^{2}$ In addition, AP has been identified as a contributing factor in inducing epigenetic alterations, along with respiratory, neurological, psychiatric and musculoskeletal diseases. ${ }^{34}$ Recent evidence suggests that an increased exposure to $\mathrm{PM}_{2.5}$ is also linked to chronic cardiometabolic comorbidities that have been associated with poor prognosis and death in patients with COVID-19. Furthermore, the cardiorespiratory system is significantly affected by both short-term and 
long-term ambient AP exposure. ${ }^{6}$ Thus, AP should be considered one of several major modifiable risk factors in the prevention and management of cardiovascular disease.

The underpinning mechanisms of AP on morbidity and mortality are associated with chronic systemic inflammation and oxidative stress, ${ }^{89}$ as well as genetic and epigenetic pathways. ${ }^{8}$ The development of chronic cardiovascular disease can be instigated via three potential pathways: a 'spill over' of proinflammatory or oxidative stress mediators generated in the lungs into the systemic circulation, the incitement of autonomic nervous system imbalance and the penetration of certain particles (ultrafine particles $\mathrm{PM}_{0.1}$ ) or components (soluble metals and organic compounds) directly into the cardiovascular tissues. ${ }^{10}$ These three factors can lead to atheroma progression, endothelial dysfunction, impaired fibrinolysis, platelet hyper-reactivity and possibly arrhythmogenesis. ${ }^{7}$

An active lifestyle with regular physical activity and exercise is known to be beneficial to health. However, the most accessible forms of exercise, such as walking, running and cycling, are often performed outdoors, which means an increased exposure to urban AP. ${ }^{11} 12$ Although the beneficial aspects of exercise can be potentially dampened if conducted in AP, exercise recommendations, such as those given by the American College of Sports Medicine, do not take into account the harmful effect of $\mathrm{AP}^{11}$ An increased risk of cardiorespiratory function, immune function and exercise performance disruption has been associated with the combination of $\mathrm{AP}$ and exercise. ${ }^{13}$ Moreover, increased ventilation during exercise causes a greater influx of air and pollutants into the airways and those might even reach systemic circulation. ${ }^{1415}$ A 12-week aerobic training programme in an urban environment with high traffic-related AP exposure increased markers of respiratory and systemic inflammation (leucocytes count, neutrophil counts and exhaled nitric oxide). These changes positively correlated with personal $\mathrm{PM}_{0.1}$ exposure during training. ${ }^{16}$ Even a short duration of exercise $(20 \mathrm{~min})$ near a busy roadway is sufficient to significantly increase blood levels of volatile organic compounds (toluene, ethylbenzene and xylene). ${ }^{17}$ Furthermore, 5 days of aerobic outdoor exercise significantly impaired nasal mucociliary clearance in the street runners group when compared with the forest runners group. ${ }^{18}$ This suggests that regular outdoor exercise in AP can be potentially harmful to cardiorespiratory health.

The adverse effect of AP on cardiovascular health might also be linked to alterations in autonomic nervous system activity. The relationship between heart rate variability (HRV), as a tool for the cardiac autonomic activity assessment, and increased risk of cardiovascular mortality and morbidity has been recognised. ${ }^{19}$ Five consecutive 8-hour days spent in an AP area caused a significant reduction in HRV. However, whether this effect is caused directly by AP or via other factors, such as oxidative stress, is unclear. ${ }^{20}$ Furthermore, previous research has observed that several hours of exposure to increased levels of $\mathrm{PM}_{0.1}$ and $\mathrm{PM}_{2.5}$ concentrations may affect HRV and induce acute pathophysiological responses. ${ }^{21}$ This fact is primarily evident in individuals with increased risk of cardiovascular diseases. $^{22} 23$ Moreover, a consistent inverse relationship was found for the level of AP and time-domain HRV variables, that is, HRV decreased when pollutant levels increased. ${ }^{20}$ In contrast, the associations between ambient concentrations of $\mathrm{PM}_{2.5}$ and HRV were not definitively confirmed in a separate review study. ${ }^{24}$

Osteoporosis has become a serious disease worldwide. Evidence suggests that there are adverse effects of AP on osteoporosis among the industrial population. ${ }^{25}$ By contrast, the total running distance and frequency rank are considered beneficial to body mass density (BMD) ${ }^{26}$ However, a high total running distance and frequency has been shown to cause BMD impairment, particularly in the lumbar spine region. ${ }^{27} 28$ Therefore, the effect of AP and regular running on the development of osteoporosis can depend on overall running volume, with a potential $U$ risk curve. Qiao et $a l^{25}$ suggests that physical activity, such as running, may weaken the adverse effects of AP on osteoporosis. However, it is not clear whether regular running is beneficial to bone health, independent of ambient AP.

The aim of the presented physiological and anthropometric perspectives of this multidisciplinary Healthy Aging in Industrial Environment Study - Program 4 (4HAIE) research project is to investigate the long-term influence of AP on health-related variables such as: biochemical markers of inflammation and oxidative stress, cardiorespiratory fitness level, blood pressure (BP), ventilatory (lung) function, cardiac autonomic regulation and body composition in regular runners $(>10 \mathrm{~km}$ of running per week for more than 6 weeks prior to the tests) and inactive individuals. Both groups are recruited from either the heavy industry area of Silesia (Czech Republic) with high AP or the area of South Bohemia (Czech Republic) with low AP.

\section{METHODS}

\section{Study design}

The presented study protocol describes the physiological and anthropometric perspectives of the 4HAIE. Because of the specific aims and measures, participants recruited for 4HAIE are a separate cohort to programmes $1-3$. The 4HAIE study is intended to be a single-centre, prospective, longitudinal and multidisciplinary cohort study investigating the influence of AP on the incidence of sportsrelated injuries, physical (in)activity, health and quality of life across the lifespan. The presented physiological and anthropometric section describes the first wave of measurement. The main aim of the presented study is a cross-sectional analysis of the health outcome differences between runners living permanently in low versus high air-polluted regions. Additionally, the possible benefits of regular running in a high air-polluted region are considered, which will be compared with inactive individuals in 
Table 1 Overview of 4 HAIE study measurements and time points for data collection

\begin{tabular}{|c|c|c|c|c|c|c|c|}
\hline \multirow[b]{2}{*}{ Time point } & \multicolumn{2}{|c|}{ Screening } & \multicolumn{2}{|c|}{$\begin{array}{l}\text { Laboratory } \\
\text { examination }\end{array}$} & \multicolumn{3}{|c|}{ Follow-up } \\
\hline & $\begin{array}{l}\text { Initial contact by } \\
\text { telephone and } \\
\text { email }\end{array}$ & $\begin{array}{l}\text { Prelaboratory } \\
\text { (in situ) }\end{array}$ & Day 1 & Day 2 & 6 months & 12 months & Ongoing \\
\hline Eligibility & $x$ & & & & & & \\
\hline Enrolment & $x$ & & & & & & \\
\hline Fitbit assessment & & & & & & & $x$ \\
\hline Blood pressure & & & $x$ & & & & \\
\hline GXT & & & $x$ & & & & \\
\hline Urine samples & & & & $x$ & & & \\
\hline Biomechanics & & & & $x$ & & & \\
\hline Cognitive function testing & & & & $x$ & & & \\
\hline MRI & & & & $x$ & & & \\
\hline Injury incidence & & & & $x$ & $x$ & $x$ & $x$ \\
\hline
\end{tabular}

GXT, graded exercise test; 4HAIE, Healthy Aging in Industrial Environment Study - Program 4; HRV, heart rate variability; PAR-Q, Physical Activity Readiness Questionnaire.

the same region. Overall, the 4HAIE project aims at the following areas of investigation: physiological, anthropometric, biomechanical, behavioural and neurocognitive (table 1). The biomechanical, behavioural and neurocognitive perspectives are beyond the scope of this article and will be presented elsewhere.

\section{Study population}

Participants are adults (age 18-65 years) who live for at least 5 years in a high air-polluted (Moravian-Silesian) or low air-polluted (South Bohemia) region of the Czech Republic. Runners and inactive individuals are recruited from both regions with high and low AP (figure 1). Sociodemographic characteristics of participants are in

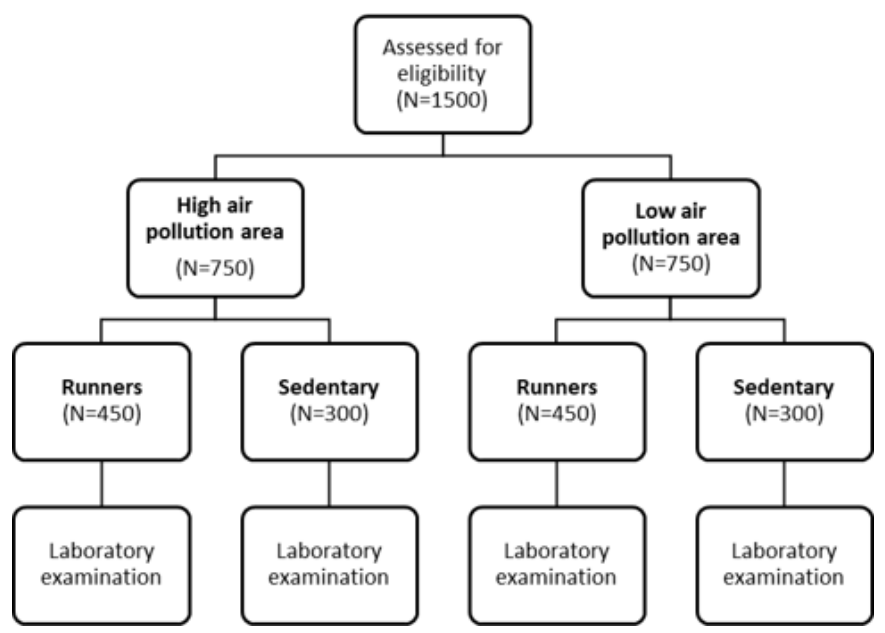

Figure 1 Flow chart of the study process. accordance with the sociodemographic characteristics of the population. The number of participants for each age decade will be equal.

- Inclusion criteria - runners: running as a main exercise activity, $>150$ min of moderate or $>75$ min of strenuous physical activity per week (or an equivalent combination of moderate and strenuous physical activity), ${ }^{29}$ $>10 \mathrm{~km}$ running per week for at least 6 weeks prior to the tests, intending to continue running for next 12 months, permanent ( $>5$ years) whole-year residency in the determined areas, not planning to move away from the determined areas during the next 12 months, with internet access and using a smartphone (with iOS or Android 5.0 or higher).

- Inclusion criteria - inactive individuals: $<150 \mathrm{~min}$ of moderate or $<75 \mathrm{~min}$ of strenuous exercise per week, capable of running, but running irregularly and/or less than 6 weeks prior to the tests, no contraindications to exercise, permanent ( $>5$ years) whole-year residency in the determined areas, not planning to move away from the determined areas during the next 12 months, with internet access and using a smartphone (with iOS or Android 5.0 or higher).

- Exclusion criteria - runners and inactive individuals: acute (within 6 weeks) health condition (pain, injury and surgery) preventing from physical activity, any other acute disease, pregnancy, radiological examination within the last 7 days, artificial pacemaker, radioactive, surgical or any other device/implant, insulin pump and smoking. 


\section{Participant and public involvement}

This research is conducted without the participants' involvement. Participants are not invited to comment on the study design, nor are they consulted to develop participant relevant outcomes or interpret the results. Furthermore, participants are not invited to contribute to the writing or editing of this document for readability or accuracy. Results that are immediately available are presented to participants with a basic explanation at the conclusion of each measurement. Other results requiring a deeper analysis are available on request.

\section{High air-polluted versus low air-polluted areas}

There are considerable regional differences in terms of air quality within the Czech Republic. ${ }^{30-33}$ The MoravianSilesian region is shown to have the highest long-term values of suspended coarse particulate matter $\left(\mathrm{PM}_{10}\right)$, $\mathrm{PM}_{2.5}, \quad \mathrm{NO}_{2}$ and benzo[a]pyrene. However, South Bohemia is considered the region with the lowest $\mathrm{AP} .^{34}$ For example, the average annual concentrations of $\mathrm{PM}_{10}$ and $\mathrm{PM}_{2.5}$ in 2018 in Ostrava-Radvanice (Moravian-Silesian region) were 44.0 and $36.8 \mu \mathrm{g} / \mathrm{m}^{3} /$ year, respectively, whereas in Ceske Budejovice (South Bohemia region), they were 19.8 and $16.0 \mu \mathrm{g} / \mathrm{m}^{3}$ /year, respectively. Additionally, in 2018, the average annual concentration of $\mathrm{NO}_{2}$ was substantially higher in Ostrava-Radvanice than in Ceske Budejovice (21.7 vs $14.9 \mu \mathrm{g} / \mathrm{m}^{3}$, respectively), and benzo[a]pyrene concentrations in Ostrava-Radvanice were more than seven times greater than values in Ceske Budejovice ( 7.7 vs $1.1 \mathrm{ng} / \mathrm{m}^{3} /$ year).$^{35}$

\section{Data collection}

Air pollution

The updated level of AP in both the Moravian-Silesian and South Bohemia regions during the data collection phase will be acquired from the Czech Hydrometeorological Institute.

\section{Biochemical analysis}

Fasting blood samples $(30 \mathrm{~mL})$ are collected from the antecubital vein in the morning hours (06:30-07:00) within the physiology laboratory. Biomarkers previously shown to be associated with chronic diseases are analysed:

- Basic analysis: erythrocytes, leucocytes, thrombocytes, haemoglobin, haematocrit, total cholesterol, lowdensity and high-density lipoprotein, triglycerides, free fatty acids, glucose, glycated haemoglobin, fibrinogen and carbohydrate-deficient transferrin.

- Oxidative stress: total antioxidative capacity, superoxide dismutase, glutathione peroxidase, malondialdehyde, glutathione and glutathione disulphide.

- Inflammation: high-sensitive $\mathrm{C}$ reactive protein, highsensitive interleukin-6, interleukin-1 $\beta$, interleukin-10, interleukin-1 receptor antagonist, tumour necrosis factor- $\alpha$, adiponectin, leptin and brain-derived neurotrophic factor.

The biochemical analysis is provided by an external specialised and certified biochemical laboratory with long-term experience in clinical analysis and research projects.

\section{Graded exercise test (GXT)}

Participants will perform a laboratory GXT on a motorised treadmill (Rodby RL 2500E) in order to determine maximum aerobic power $\left(\dot{V} \mathrm{O}_{2 \max }\right)$, the first $\left(\mathrm{VT}_{1}\right)$ and the second ventilatory threshold $\left(\mathrm{VT}_{2}\right)$, total time to exhaustion and respiratory exchange ratio. Prior to the GXT, participants complete $3 \mathrm{~min}$ of walking at $5.0 \mathrm{~km} /$ hour to familiarise themselves with the treadmill. The GXT protocol then commences at $6.0 \mathrm{~km} /$ hour, with speed subsequently increasing by $1.0 \mathrm{~km}$ /hour every minute (inclination remaining at 1\%) until volitional exhaustion. Expired air is continuously monitored to analyse $\mathrm{O}_{2}$ and $\mathrm{CO}_{2}$ concentrations during the GXT with a breathby-breath system (Blue Cherry, Geratherm Medical AG, Germany). The highest average $\mathrm{O}_{2}$ consumption measured over a 30 s period is used to determine $\dot{V} \mathrm{O}_{2 \max }$. Gas exchange measurements are also used to quantify $\mathrm{VT}_{1}$ and $\mathrm{VT}_{2}$. $\mathrm{VT}_{1}$ is defined as the first increase in ventilation (VE) accompanied by a minimum of the oxygen equivalent $\left(\mathrm{VE} / \mathrm{VO}_{2}\right)$ without an increase in the $\mathrm{CO}_{2}$ equivalent $\left(\mathrm{VE} / \mathrm{VCO}_{2}\right)$. A second sharp increase in ventilation (VE) accompanied by an increase in both $\mathrm{VE} / \mathrm{VO}_{2}$ and $\mathrm{VE} / \mathrm{VCO}_{2}$ is used to define $\mathrm{VT}_{2}{ }^{36}$ Heart rate (HR) is measured using a chest belt monitor (Polar Electro H9, Kempele, Finland). Perceived effort is measured using the 20-point Borg scale. All sessions are conducted in the afternoon, at least 3 hours after the participants' last meal and in a thermally controlled laboratory $\left(21^{\circ} \mathrm{C}, 40 \%\right.$ relative humidity). Each participant is advised not to participate in any vigorous activity 24 hours prior to the test.

Prior to completing the GXT, if participants do not pass the Physical Activity Readiness Questionnaire, they are not allowed to perform the GXT unless explicit permission (given by a medical doctor) is provided. BP is also checked before the GXT. If the BP values are $\geq 150 / 90 \mathrm{~mm}$ $\mathrm{Hg}$, the participant is not allowed to perform GXT, but continues in the study protocol.

\section{Blood pressure}

Participants are instructed to avoid caffeinated beverages at least $60 \mathrm{~min}$ before BP measurements. The BP measurements commence following $\geq 10 \mathrm{~min}$ of rest in a quiet room. Participants sit with back straight and supported, with feet flat on the floor and legs uncrossed, keeping left arm supported on a table at heart level. The bottom of the cuff is placed directly above the antecubital fossa. $\mathrm{BP}$ is recorded repeatedly three times $1-2 \mathrm{~min}$ apart. The Nissei DM 3000 device is used for the BP measurement. This procedure is in line with the American College of Cardiology, American Heart Association and European Society of Hypertension recommendations. ${ }^{3738}$

\section{Spirometry}

Prior to the spirometry test, the spirometer (Blue Cherry, Geratherm Medical AG) is calibrated according to the 


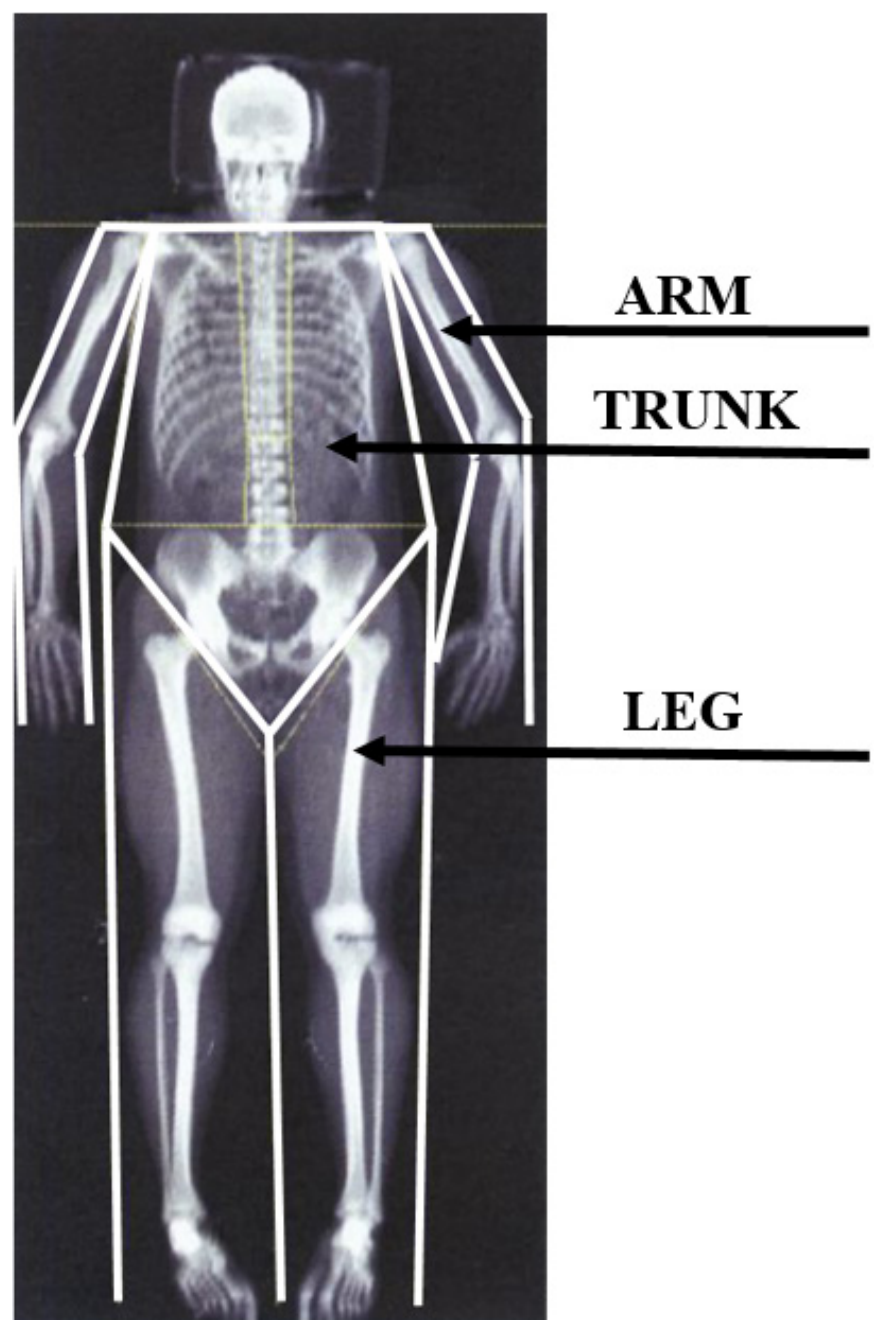

Figure 2 Whole body scan.

manufacturer instructions. The test is then explained, and the appropriate technique is demonstrated to the participants. Participants are relaxed, seated erect, using a mouthpiece and wearing a nose clip. The vital capacity manoeuvre starts with five tidal breaths, followed by an inspiratory manoeuvre to total lung capacity with no hesitation and then a full expiration to residual volume. The laboratory staff encourages participants to reach maximal inspiratory and expiratory volumes. This procedure is repeated three times with at least $1 \mathrm{~min}$ break apart. The spirometry test is performed in line with the American Thoracic Society and European Respiratory Society recommendations. ${ }^{39}$ Other lung function variables, such as peak expiratory flow or forced expiratory volume in $1 \mathrm{~s}$, will be evaluated since their adverse relationships to long-term exposure to ambient AP have been observed. ${ }^{40}$

\section{Cardiac autonomic regulation}

HRV is used to evaluate cardiac autonomic regulation. A Bittium Faros device (Bittium Inc, Oulu, Finland) collects a single-channel ECG from two electrodes placed on a chest belt. The short-term (10 min) ECG is recorded in a quiet room after waking until 07:00. Participants remain resting in a supine position with no external disturbances

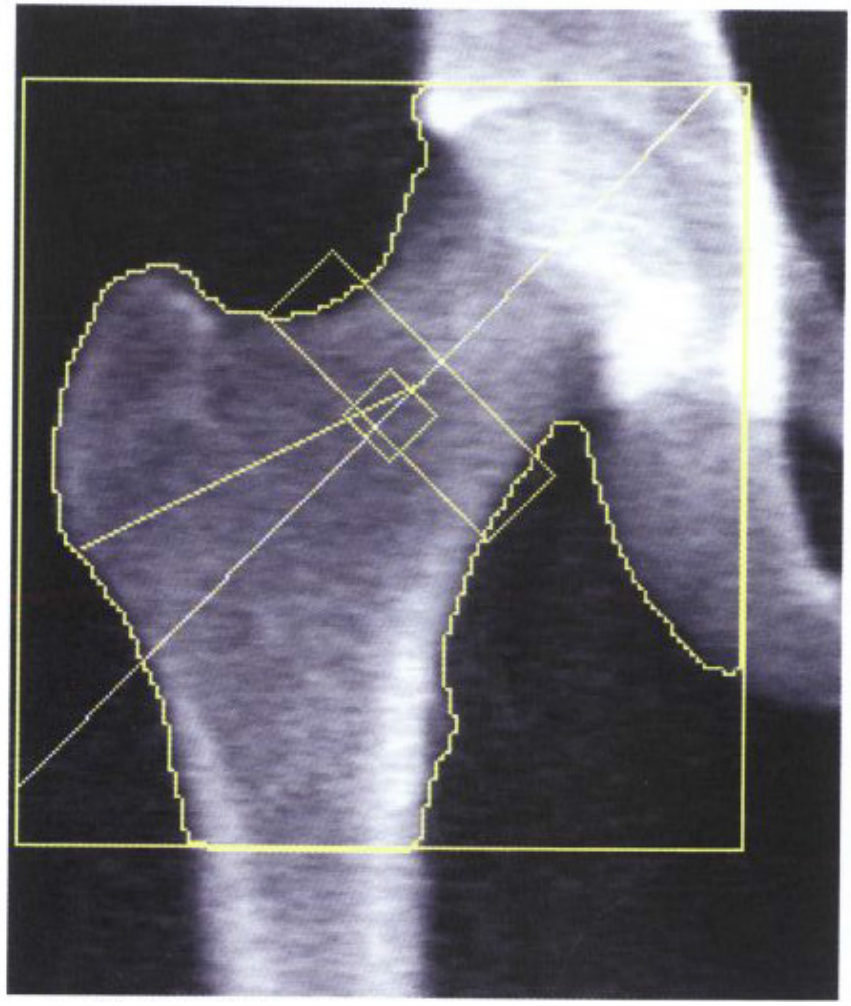

Figure 3 Hip scan.

during the ECG recording. The first half of the ECG recording time is designed to induce steady state conditions and is not included in the HRV analysis (in most participants $5 \mathrm{~min}$ ). ECG data are imported into Kubios HRV Premium, which automatically detects the R-wave time instants by applying the built-in QRS detection algorithm. ${ }^{41}$ Before R-wave time instant extraction, the R-wave is interpolated at $2000 \mathrm{~Hz}$ to improve the time resolution of the detection. The standard time/frequency-domain HRV variables are analysed from the $5 \mathrm{~min}(300 \mathrm{~s})$ long ECG sequence according to the task force recommendations. ${ }^{42}$ Prior to the HRV analysis, the ECG records and RR interval times series are visually checked for artefacts, and an automated algorithm ${ }^{43}$ for artefact detection is also used through the Kubios software. Artefacts including missing, extra or misaligned beat detections, as well as ectopic beats such as premature ventricular contractions or other arrhythmias, are filtered out from the RR interval time series used for the HRV analysis. Furthermore, slow non-stationary oscillations in RR intervals are detrended with smoothness priors. ${ }^{44}$ Main time domain measures of interest include: the SD of all normal-to-normal RR intervals and the root mean square of successive differences of normal-to-normal RR intervals. Main frequency domain components will include the low-frequency, $0.04-0.15 \mathrm{~Hz}$, and high-frequency, $0.15-0.4 \mathrm{~Hz}$, spectral power. ${ }^{42}$

\section{Anthropometry}

Anthropometric measurements include basic anthropometric parameters (body height and body mass), hydration status and body composition. All measurements are 
taken in the morning; the participants are measured in sports clothing (shorts and t-shirt) and barefoot. The standard conditions for the bioelectrical impedance analysis (BIA) method measurements are provided by the specific schedule of the study protocol; that is, the participants are placed in a supervised accommodation at the research centre about 15 hours prior to the BIA measurement. First, body height is measured using the InBody 370 stadiometer (Biospace, South Korea). This is followed by body mass and hydration status (total body water, intracellular and extracellular water), which are measured using the InBody 770 bioimpedance multifrequency scale device (Biospace). Lastly, body composition is measured using the dual-energy X-ray absorptiometry method. The measurement is executed using the Hologic Horizon A bone densitometer (Hologic Discovery A, Waltham, Massachusetts, USA). A whole-body scan is used for the analysis of body composition, including the segmental analysis, hip scans (right and left) and lumbar scan (L1-L4). The measured parameters are body fat, fat free mass, bone mineral content and bone mineral density. The position during measurement is presented in figure 2; figures 3-4 present the scans of the individual areas measured.

\section{Data analysis}

Sample size is not calculated since the number of participants in total as well as in each subgroup (figure 1) are considered sufficient to avoid an underpowered study. The number of participants is deliberately high because a follow-up, long-term prospective study is planned and some drop-outs are expected for the second wave of measurements.

The high air-polluted versys low air-polluted group data are assessed for differences in health-related and performance variables using adjusted and unadjusted mixed methods regression, with potential contributing variables such as age, sex and physical activity level. All data are checked for distribution and homoscedasticity. Where these two assumptions are violated, data are analysed using a non-parametric analysis. Analyses are performed using IBM SPSS Statistics 24 and GraphPad Prism 9.0.0 with statistical significance set at $\mathrm{p}<0.05$.

\section{DISCUSSION}

Ambient AP is a global environmental health problem, which caused around 4.2 million premature deaths worldwide in 2016, both in cities and rural areas. ${ }^{45}$ Exposure to $\mathrm{PM}_{2.5}$ or less in diameter and ozone has been associated with an increased risk of death, even at levels below the air quality standards annual mean limits for $\mathrm{PM}_{2.5}{ }^{46} 47$ AP exposure may suppress the early immune response to infection, including infectious respiratory diseases such as influenza, pneumonia and severe acute respiratory syndrome. Furthermore, an increase of only $1 \mu \mathrm{g} / \mathrm{m}^{3}$ in $\mathrm{PM}_{2.5}$ has been significantly associated with an $8 \%(95 \%$ CI $2 \%$ to $15 \%$ ) increase in the COVID-19 death rate. ${ }^{5}$

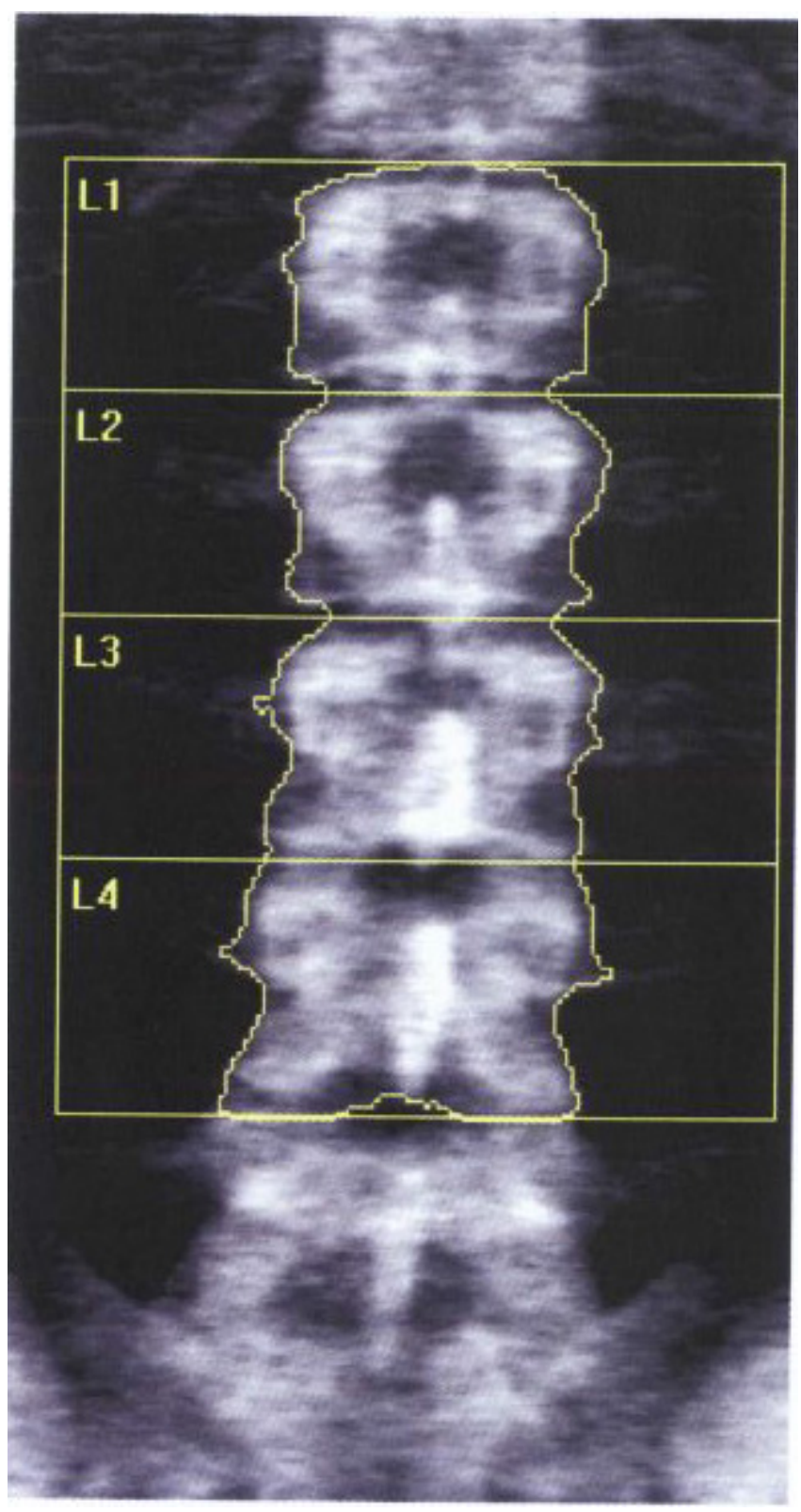

Figure 4 Spine scan (L1-L4).

Regular physical activity and exercise have been proven to produce a number of health and fitness related benefits $^{48}$ and are therefore integral to all well-being guidelines within primary and secondary prevention, ${ }^{29}$ as well as rehabilitation for patients suffering from chronic diseases. ${ }^{49}$ Additionally, cardiorespiratory fitness, as well as strength, are strongly related to mortality risk. ${ }^{51-53}$ Since physical activity and/or exercise is commonly performed in outdoor conditions, a question arises about the negative health effects of greater long-term exposure to AP from habitual outdoor exercise. ${ }^{1415}$

This study is unique as it aims to investigate the global environmental problem (ie, AP) in large cohorts of runners and inactive individuals permanently living in areas with high and low AP. It has been suggested that a broader strategy beyond healthcare that includes investments in social services, improved environmental quality 
(eg, AP), and health behaviours could improve the health of communities as well as bring substantial economic benefits. ${ }^{555}$ Additionally, this interdisciplinary research project is intended also to set up a longitudinal prospective study with follow-up waves of measurements. The results might show the real cost-effect ratio of outdoor endurance exercise performed habitually in an airpolluted environment. From the long-term perspective, it can be hypothesised that the health benefits of regular outdoor physical activity will be diminished by adverse environmental factors. However, it can further be hypothesised that regular outdoor physical activity will decrease the adverse health effects of AP. A deeper understanding of the relationship between AP and exercise is important for all physically active individuals, as well as authorities publishing physical activity recommendations for the general population and public services authorities in affected regions.

\section{ETHICS AND DISSEMINATION}

The 4HAIE study is conducted in accordance with the Declaration of Helsinki. The study protocol has already been approved by the Ethics Committee of the University of Ostrava $(3 / 2018)$. A detailed participant information sheet is provided to each individual prior to them providing written informed consent. The study poses little to no risk to participants.

The findings of this study will be disseminated at regional and international conferences, in peer-reviewed journals and via social and broadcast media.

\section{Author affiliations}

${ }^{1}$ Department of Human Movement Science, University of Ostrava, Ostrava, Czech Republic

${ }^{2}$ Department of Epidemiology and Public Health, University of Ostrava, Ostrava, Czech Republic

${ }^{3}$ Department of Genetic Toxicology and Epigenetics, Institute of Experimental Medicine, Czech Academy of Sciences, Prague, Czech Republic

${ }^{4}$ Centre for Epidemiological Research, University of Ostrava, Ostrava, Czech Republic

${ }^{5}$ Institute of Human Movement Science, Sport \& Health, Exercise Physiology, Training \& Training Therapy Research Group, University of Graz, Graz, Austria

\section{Twitter Lukas Cipryan @LukasCipryan}

Acknowledgements The authors give a special thanks to Associate Professor Steriani Elavsky and all other colleagues for their revision and comments.

Contributors LC and PK conceptualised and designed the study, drafted the initial manuscript and critically revised it; TD, MZ, MK, RS and DJ reviewed the manuscript; VJ critically revisited the heart rate variability and methodological part of this manuscript for important intellectual content; PH critically revisited the manuscript for important intellectual content.

Funding This publication is based on information provided by Program 4 of the research project 'Healthy Aging in Industrial Environment (HAIE)' with a registration number CZ.02.1.01/0.0/0.0/16_019/0000798, which was founded by the Europe Union via the Ministry of Education Youth and Sports (Czech Republic).

Competing interests None declared.

Patient and public involvement Patients and/or the public were not involved in the design, or conduct, or reporting, or dissemination plans of this research.

Patient consent for publication Not required.

Provenance and peer review Not commissioned; externally peer reviewed.
Open access This is an open access article distributed in accordance with the Creative Commons Attribution Non Commercial (CC BY-NC 4.0) license, which permits others to distribute, remix, adapt, build upon this work non-commercially, and license their derivative works on different terms, provided the original work is properly cited, appropriate credit is given, any changes made indicated, and the use is non-commercial. See: http://creativecommons.org/licenses/by-nc/4.0/.

ORCID iD

Lukas Cipryan http://orcid.org/0000-0002-2403-8797

\section{REFERENCES}

1 World Health Organization, 2019. Available: https://www.who.int/ health-topics/air-pollution\#tab=tab_1

2 Brook RD, Newby DE, Rajagopalan S. Air pollution and cardiometabolic disease: an update and call for clinical trials. Am J Hypertens 2018;31:1-10.

3 Thurston GD, Kipen H, Annesi-Maesano I, et al. A joint ERS/ATS policy statement: what constitutes an adverse health effect of air pollution? an analytical framework. Eur Respir J 2017;49:1600419.

4 Shepherd A, Mullins JT. Arthritis diagnosis and early-life exposure to air pollution. Environ Pollut 2019;253:1030-7.

5 Wu X, Nethery RC, Sabath BM, et al. Exposure to air pollution and COVID-19 mortality in the United States: a nationwide crosssectional study. medRxiv 2020. doi:10.1101/2020.04.05.20054502. [Epub ahead of print: 07 Apr 2020].

6 Yang Y, Ruan Z, Wang X, et al. Short-Term and long-term exposures to fine particulate matter constituents and health: a systematic review and meta-analysis. Environ Pollut 2019;247:874-82.

7 Newby DE, Mannucci PM, Tell GS, et al. Expert position paper on air pollution and cardiovascular disease. Eur Heart J 2015;36:83-93.

8 Yang D, Yang X, Deng F. Ambient air pollution and biomarkers of health effect. In: Advances in experimental medicine and biology. Springer New York LLC, 2017: 59-102.

9 Bai Y, Sun Q. Fine particulate matter air pollution and atherosclerosis: mechanistic insights. Biochim Biophys Acta 2016;1860:2863-8.

10 Franklin BA, Brook R, Arden Pope C. Air pollution and cardiovascular disease. Curr Probl Cardiol 2015;40:207-38.

11 Garber CE, Blissmer B, Deschenes MR, et al. American College of sports medicine position stand. quantity and quality of exercise for developing and maintaining cardiorespiratory, musculoskeletal, and neuromotor fitness in apparently healthy adults: guidance for prescribing exercise. Med Sci Sports Exerc 2011;43:1334-59.

12 Tainio M, de Nazelle AJ, Götschi T, et al. Can air pollution negate the health benefits of cycling and walking? Prev Med 2016;87:S54.

13 Qin F, Yang Y, Wang S-T, tao WS, et al. Exercise and air pollutants exposure: a systematic review and meta-analysis. Life Sci 2019;218:153-64.

14 Daigle CC, Chalupa DC, Gibb FR, et al. Ultrafine particle deposition in humans during rest and exercise. Inhal Toxicol 2003;15:539-52.

15 Pierson WE, Covert DS, Koenig JQ, et al. Review: implications of air pollution effects on athletic performance. Atmospheric Environment 1986;20:2033-8.

16 Bos I, De Boever P, Vanparijs J, et al. Subclinical effects of aerobic training in urban environment. Med Sci Sports Exerc 2013;45:439-47.

17 Blair C, Walls J, Davies NW, et al. Volatile organic compounds in runners near a roadway: increased blood levels after short-duration exercise. Br J Sports Med 2010;44:731-5.

18 Cavalcante de Sá M, Nakagawa NK, Saldiva de André CD, et al. Aerobic exercise in polluted urban environments: effects on airway defense mechanisms in young healthy amateur runners. $J$ Breath Res 2016;10:046018.

19 De Meersman RE, Stein PK. Vagal modulation and aging. Biol Psychol 2007;74:165-73.

20 Shutt RH, Kauri LM, Weichenthal S, et al. Exposure to air pollution near a steel plant is associated with reduced heart rate variability: a randomised crossover study. Environmental Health 2017;16:1-10.

21 Breitner S, Peters A, Zareba W, et al. Ambient and controlled exposures to particulate air pollution and acute changes in heart rate variability and repolarization. Sci Rep 2019;9:1-12.

22 Bind M-A, Peters A, Koutrakis P, et al. Quantile regression analysis of the distributional effects of air pollution on blood pressure, heart rate variability, blood lipids, and biomarkers of inflammation in elderly American men: the normative aging study. Environ Health Perspect 2016;124:1189-98.

23 Byun H-M, Colicino E, Trevisi L, et al. Effects of air pollution and blood mitochondrial DNA methylation on markers of heart rate variability. J Am Heart Assoc 2016;5:1-10. 
24 Buteau S, Goldberg MS. A structured review of panel studies used to investigate associations between ambient air pollution and heart rate variability. Environ Res 2016;148:207-47.

25 Qiao D, Pan J, Chen G, et al. Long-term exposure to air pollution might increase prevalence of osteoporosis in Chinese rural population. Environ Res 2020;183:109264.

26 Taunton JE, Ryan MB, Clement DB, et al. A prospective study of running injuries: the Vancouver Sun Run "In Training" clinics. Br J Sports Med 2003;37:239-44.

27 Barrack MT, Fredericson M, Tenforde AS, et al. Evidence of a cumulative effect for risk factors predicting low bone mass among male adolescent athletes. Br J Sports Med 2017;51:200-5.

28 Tenforde AS, Parziale AL, Popp KL, et al. Low bone mineral density in male athletes is associated with bone stress injuries at anatomic sites with greater trabecular composition. Am J Sports Med 2018;46:30-6.

29 Riebe D. Guidelines for exercise testing and prescription (ACSM). 10 edn. Philadelphia: Wolters Kluwer Health | Lippincott Williams \& Wilkins, 2018.

30 Francová A, Chrastný V, Vítková M, et al. Health risk assessment of metal(loid)s in soil and particulate matter from industrialized regions: A multidisciplinary approach. Environ Pollut 2020;260:114057.

31 Modrá H, Ulmann V, Caha J, et al. Socio-Economic and environmental factors related to spatial differences in human nontuberculous mycobacterial diseases in the Czech Republic. Int $J$ Environ Res Public Health 2019;16. doi:10.3390/ijerph16203969. [Epub ahead of print: 1710 2019].

32 Švecová V, Topinka J, Solanský I, et al. Relation between personal exposure and outdoor concentrations of carcinogenic polycyclic aromatic hydrocarbons during smog episode. Cent Eur J Public Health 2019;27:305-11.

33 Hůnová I. Ambient air quality in the Czech Republic: past and present. Atmosphere 2020;11:214.

34 Skachová H, Vlasaková L. Air Pollution in the Czech Republic 2018. Czech Hydrometeorological Institute - Air Quality Division, 2018. Available: http://portal.chmi.cz/files/portal/docs/uoco/isko/grafroc/ $18 \mathrm{groc} / \mathrm{gr} 18 \mathrm{cz} / \mathrm{KO}$ rocenka_2018.pdf [Accessed $31 \mathrm{Mar} 2020]$.

$35 \mathrm{CHMI}$. Czech Hydrometeorological Institute. Available: http://portal. chmi.cz/? I=en

36 Binder RK, Wonisch M, Corra U, et al. Methodological approach to the first and second lactate threshold in incremental cardiopulmonary exercise testing. Eur J Cardiovasc Prev Rehabil 2008;15:726-34.

37 Casey DE, Thomas RJ, Bhalla V, et al. 2019 AHAVACC clinical performance and quality measures for adults with high blood pressure: a report of the American College of Cardiology/American heart association Task force on performance measures. Circ Cardiovasc Qual Outcomes 2019;12:e000057.

38 Parati G, Stergiou GS, Asmar R, et al. European Society of hypertension guidelines for blood pressure monitoring at home: a summary report of the second international consensus conference on home blood pressure monitoring. J Hypertens 2008;26:1505-26.
39 Graham BL, Steenbruggen I, Miller MR, et al. Standardization of spirometry 2019 update. An official American thoracic Society and European respiratory Society technical statement. Am J Respir Crit Care Med 2019;200:e70-88.

40 Wu S, Deng F, Hao Y, et al. Fine particulate matter, temperature, and lung function in healthy adults: findings from the HVNR study. Chemosphere 2014;108:168-74.

41 Pan J, Tompkins WJ. A real-time QRS detection algorithm. IEEE Trans Biomed Eng 1985;32:230-6. doi:10.1109/TBME.1985.325532

42 Malik M, Bigger J, Camm A, et al. Heart rate variability. standards of measurement, physiological interpretation, and clinical use. Task force of the European Society of cardiology and the North American Society of pacing and electrophysiology. Eur Heart J1996.

43 Lipponen JA, Tarvainen MP. A robust algorithm for heart rate variability time series artefact correction using novel beat classification. J Med Eng Technol 2019;43:173-81.

44 Tarvainen MP, Ranta-Aho PO, Karjalainen PA. An advanced detrending method with application to HRV analysis. IEEE Trans Biomed Eng 2002;49:172-5.

45 World Health Organization. Ambient (outdoor) air pollution. fact sheets, 2018. Available: https://www.who.int/news-room/fact-sheets/ detail/ambient-(outdoor)-air-quality-and-health [Accessed 17 Feb 2020].

46 Beelen R, Raaschou-Nielsen O, Stafoggia M, et al. Effects of longterm exposure to air pollution on natural-cause mortality: an analysis of 22 European cohorts within the multicentre escape project. Lancet 2014;383:785-95.

47 Di Q, Wang Y, Zanobetti A, et al. Air pollution and mortality in the Medicare population. N Engl J Med 2017;376:2513-22.

48 Ehrman JK, Gordon PM, Visich PS, et al. Clinical exercise physiology. Champaign: Human Kinetics, 2019.

49 Pedersen BK, Saltin B. Exercise as medicine - evidence for prescribing exercise as therapy in 26 different chronic diseases. Scand J Med Sci Sports 2015;25 Suppl 3:1-72.

50 Pedersen BK, Saltin B. Evidence for prescribing exercise as therapy in chronic disease. Scand J Med Sci Sports 2006;16:3-63.

51 Kim Y, White T, Wijndaele K, et al. The combination of cardiorespiratory fitness and muscle strength, and mortality risk. Eur $J$ Epidemiol 2018;33:953-64.

52 Lee DAY, Rhee E-J, Cho JH, et al. Appropriate amount of regular exercise is associated with a reduced mortality risk. Med Sci Sports Exerc 2018;50:2451-8.

53 Lee J. Associations between handgrip strength and disease-specific mortality including cancer, cardiovascular, and respiratory diseases in older adults: a meta-analysis. J Aging Phys Act 2020;28:320-31.

54 Thorpe KE, Joski P. Association of social service spending, environmental quality, and health behaviors on health outcomes. Popul Health Manag 2018;21:291-5.

55 Grabow ML, Spak SN, Holloway T, et al. Air quality and exerciserelated health benefits from reduced CAR travel in the midwestern United States. Environ Health Perspect 2012;120:68-76. 